\title{
Apresentação: Educação e memórias femininas: interfaces e conexões em contextos históricos ocidentais
}

\author{
Samara Mendes Araújo Silva* \\ Lia Machado Fiuza Fialho** \\ Zuleide Fernandes de Queiroz ${ }^{* * *}$
}

Em 1975, a Organização das Nações Unidas (ONU) instituiu o Ano Internacional da Mulher, conforme segue:

em 1979, a Assembleia Geral adotou a Convenção sobre a Eliminação de Todas as Formas de Discriminação contra a Mulher, frequentemente descrita como uma Carta Internacional dos Direitos da Mulher. Em seus 30 artigos, a Convenção define claramente a discriminação contra mulheres e estabelece uma agenda para ação nacional para pôr fim a tal discriminação. A Convenção considera a cultura e a tradição como forças influentes para moldar os papéis de gênero e as relações familiares, e é o primeiro tratado de direitos humanos a afirmar os direitos reprodutivos das mulheres. (ONU, s. d.).

Também declarou o período de 1976 a 1985 como sendo a Década das Mulheres ${ }^{1}$.

No Brasil era empreendida a primeira Comissão Parlamentar Mista de Inquérito (CPMI) para examinar a situação da mulher em todos os setores de atividade em 1977-1978. Dentre as conclusões, a CPMI recomendava:

* Universidade Federal do Paraná. Setor de Educação. Curitiba, Paraná, Brasil. E-mail: samara.mendes@ig.com.br. https://orcid.org/0000-0002-2340-015X.

** Universidade Estadual do Ceará. Centro de Educação. Programa de Pós-Graduação em Educação. Fortaleza, Ceará, Brasil. E-mail: lia.fialho@uece.br. https://orcid.org/0000-0003-03939892.

*** Universidade Regional do Cariri. Mestrado Profissional em Educação. Crato, Ceará, Brasil. E-mail: zuleide.queiroz@urca.br. https://orcid.org/0000-0003-3174-4750.

1 Para maiores informações consultar o site: <https://nacoesunidas.org/acao/mulheres $>$. Acesso em: 08 fev. 2018. 
- Estabelecimento de igualdade de oportunidades para ambos os sexos quanto a programas e currículos escolares;

- Inclusão, nos currículos escolares de todos os graus de estudo, do desenvolvimento psicossexual e análise da situação da mulher;

- Reavaliação dos livros didáticos a fim de que, se necessário, sejam reescritos para que reflitam uma imagem não estereotipada do papel da mulher na sociedade;

- Revisão dos cursos de formação e treinamento de professores para promover mudanças em atitudes preconceituosas;

- Intensificação de programas de orientação educacional visando encaminhar ambos os sexos para novas ocupações e novos papéis dentro da família e da sociedade;

- Desenvolvimento de um programa educativo para mudar atitudes do público em geral, de pais e de professores e para conscientizá-los da necessidade de igualdade de tratamento das crianças de ambos os sexos desde a mais tenra idade. (BRASIL, 1978).

As ações e políticas públicas voltadas à equidade de gêneros resultaram das demandas advindas dos Movimentos Sociais, especialmente do Movimento Feminista, e da institucionalização da História das Mulheres e dos Gêneros.

Os Movimentos Sociais tiveram ampla efervescência nas décadas de 1960-1970, proliferando ideias e ações, tanto no campo social quanto no acadêmico. No tocante a este último, fomentaram o surgimento de novos paradigmas dando origem ao que posteriormente denominou-se Nova História (Cultural e Social) "preocupada centralmente com a diversidade dos objetos e a alteridade cultural, entre sociedades e dentro de cada uma delas." (CARDOSO, 1997, p. 13), a qual expandiu perspectivas de análises e compreensões sobre o contexto sociocultural e a própria História.

Decorridos mais de 30 anos das primeiras iniciativas da sociedade ocidental, na qual a brasileira se inclui, congregar esforços e recursos de várias naturezas para alcançar a equidade de gêneros e sem a obtenção do sucesso almejado. Novas iniciativas se mostraram necessárias com urgência, em virtude das situações que cotidianamente acontecem no cenário mundial e nacional, conforme demonstram dados sobre a violência contra a mulher.

\section{NO MUNDO*...}

- A cada 2 segundos, uma garota de menos de 18 anos é forçada a se casar.

- 1 em cada 3 garotas de 13 a 15 anos sofrem com bullying regularmente.

- 15 milhões de adolescentes de 15 a 19 anos já sofreram abuso sexual. 
- 9 milhões destas garotas sofreram abuso sexual nos últimos 12 meses.

- 1 em cada 4 garotas dos EUA sofrem abuso sexual antes de completarem 16 anos.

- 1 em cada 5 jovens sofrem abuso sexual dentro das universidades dos EUA.

- 1 em cada 4 adolescentes do Reino Unido sofrem violência física pelos seus próprios namorados.

- 1 em cada 4 adolescentes francesas são vítimas de assédio pela Internet.

- 70\% das mulheres refugiadas são vítimas de violência ao longo da vida.

- 31,5\% das mulheres e garotas italianas são vítimas de violência física ou sexual.

- $43 \%$ das mulheres europeias já sofreram de assédio moral ou violência física pelos seus parceiros.

- 200 milhões de garotas e mulheres já foram obrigadas a passar por mutilação genital.

NO BRASIL **...

- 503 mulheres brasileiras são vítimas de agressão física a cada hora.

- Entre as mulheres que sofreram violência, 52\% se calaram. Apenas $11 \%$ procuraram a Delegacia da Mulher.

- Em $61 \%$ dos casos, o agressor é um conhecido; em 19\% das vezes, eram companheiros atuais das vítimas.

- $43 \%$ das agressões ocorreram dentro das casas das vítimas.

- 40\% das mulheres acima de 16 anos já sofreram algum tipo de assédio.

- 5,2 milhões de mulheres já sofreram assédio em transporte público.

- 20,4 milhões de mulheres já receberam comentários desrespeitosos nas ruas.

-2,2 milhões de mulheres já foi beijada ou agarrada sem consentimento.

- $10 \%$ das mulheres já sofreram ameaça de violência física.

- $8 \%$ das mulheres sofreram ofensa sexual.

- $4 \%$ receberam ameaça com faca ou arma de fogo.

- 3\% (ou 1,4 milhões) de mulheres sofreram espancamento ou tentativa de estrangulamento e $1 \%$ levou pelo menos um tiro.

* Pesquisa feita pela Kering Foundation. Dados referentes a 2016 e 2017.

** Pesquisa feita pelo Datafolha e encomendada pelo Fórum Brasileiro de Segurança. Dados referentes ao ano de 2016. (VIOLÊNCIA..., 2017).

Em face disto, "no dia 2 de julho de 2010, a Assembleia Geral da ONU votou por unanimidade a criação de um órgão único da ONU encarregado de acelerar os progressos para alcançar a igualdade de gênero e fortalecer a autonomia das mulheres." (ONU, s.d.), além de lançar em 2014 a Campanha Internacional 
HE FOR SHE (Eles Por Elas) para "a igualdade de gênero e o empoderamento das mulheres, tem como objetivo engajar homens e meninos para novas relações de gênero sem atitudes e comportamentos machistas" (ONU, s.d.). Desde 2015, iniciada na Argentina pelas redes sociais, pessoas começaram a se mobilizar sob a \#NiUnaMenos (Nenhuma a Menos), "pedindo que não haja mais mulheres mortas por violência machista. [...] uma campanha contra o feminicídio" (PEINADO, 2015). Essas ações e campanhas objetivam a mobilização social para a extinção da violência e discriminação fundamentadas em questões de gênero, cujas principais vítimas permanecem sendo as mulheres e pessoas Lésbicas, Gays, Bissexuais, Travestis, Transexuais e Transgêneros (LGBT).

Desse cenário carece refletir, a partir de subsídios consolidados, acerca da historicidade da formação e inserção social feminina, por isso se constituiu o dossiê "Educação feminina: história e memória". Neste dossiê, propomos compreender a Educação Feminina na interface com as complexas intersecções entre o contexto sócio-histórico e as singularidades/diversidades intranacionais e internacionais, a partir dos percursos formativos e das instituições escolares, tendo como instrumental os trabalhos produzidos por pesquisadoras da História das Mulheres em diferentes contextos históricos.

O dossiê particularmente agrega múltiplas funções - acadêmicas e sociais - nesta realidade conflituosa, em que mais uma vez os movimentos sociais devem se mobilizar para requerer que as instituições ajam e implementem ações e políticas públicas efetivas para a segurança da vida física, psicológica e emocional de tod@s. De modo que cabe ao espaço acadêmico organizar e publicizar a reflexão coerente e crítica da realidade sociocultural.

Devido à importância da temática e às décadas de invisibilidade a que foi relegada a História das Mulheres - em especial as desfavorecidas econômica e culturalmente -, as pesquisadoras assumiram nos textos que integram este dossiê o compromisso para com a Historiografia do feminino, sobretudo em relação à igualdade, à cidadania e à liberdade do gênero humano. Decidiu-se, todavia, por ampliar e aprofundar os conhecimentos por meio da análise da educação das mulheres no Brasil, na França e na Argentina, abrangendo as dinâmicas da formação destes sujeitos, atuantes em cenários socioculturais diversos e divergentes onde há permanências e conservações geracionais sobrepondo-se e convivendo e resistindo e sobre-existindo junto à e de transformações umas lentas outras abruptas.

Para a construção dos artigos, as autoras se utilizam de fontes documentais, como diários, cartas, livros de memórias, matérias de jornais, revistas de educação e de instrução destinadas às famílias e às mulheres, relatórios de autoridades educacionais, legislação educacional, fotografias etc.; e de fontes orais, como entrevistas e narrativas. As fontes aliadas a uma análise crítica e 
reflexiva permitiram a elaboração de problematizações sobre a educação de mulheres ou mesmo para as mulheres. As problematizações são propulsoras de possibilidades para o rompimento de paradigmas e para questionar dogmas e estereótipos consagrados pelo senso comum ou pelas generalizações que subjugam o feminino.

O dossiê "Educação feminina: história e memória" é composto por oito artigos que se apoiam nas fontes históricas originais e, teoricamente, na literatura já produzida acerca da história de mulheres que se debruçam sobre a natureza feminina, família, educação, profissão, mercado de trabalho, sexualidade, feminismo, subjetividades femininas, lutas por direitos políticos, resistência ao autoritarismo. Além de outros assuntos relativos ao tempo, à sociedade, à cultura em que estavam inseridas e desenvolveram a Educação Feminina.

Iniciamos com o texto "Patrimônio e matrimônio: proposta para uma nova historiografia da cultura ocidental", de Ria Lemaire, abordando

a tradição educacional feminina, transmitida oralmente de mães para filhas, das bailadas - danças primaveris registradas desde os manuscritos da Idade Média europeia [...] baseada numa arqueologia (Foucault) da gênese desse conhecimento histórico convencional, na sua revisão com critérios científicos e inserção em novos quadros históricos que mostrem e questionem continuamente, num pé de igualdade, as contribuições patrimoniais e matrimoniais para a história da cultura ocidental.

Em "Feminização do magistério e masculinização do comando educacional: estudos no Teachers College da Universidade de Columbia (1927-1935)", Mirian Jorge Warde e Ana Cristina Santos Matos Rocha concentram a análise "no Teachers College da Universidade de Columbia, instituição que, criada com foco na mulher, passa em curto tempo ao controle masculino", nas trajetórias e nas condições desiguais de profissionalização e ascensão na carreira de brasileiros e brasileiras que ali estudaram entre as décadas de 1920 a 1930.

Enquanto Joselina da Silva e Maria Simone Euclides analisam e apontam em "Falando de gênero, raça e educação: trajetórias de professoras doutoras negras de universidades públicas dos estados do Ceará e do Rio de Janeiro (Brasil)" as dificuldades de ascensão educacional e profissional das mulheres negras. "[...] apresenta um exame sobre trajetórias educacionais de professoras doutoras negras nos contextos profissionais.", e "discorre sobre racismo institucional".

No artigo "Maria Neli Sobreira: história e memória da educação em Juazeiro do Norte", Lia Machado Fiuza Fialho e Zuleide Fernandes de Queiroz 
demonstram como atuou uma madre educadora responsável pela alfabetização de meninas no sertão brasileiro no século XX "marcado pela atuação de professoras leigas no meio rural", para tal utilizaram "história oral biográfica, objetiva-se compreender a formação profissional e práticas pedagógicas empreendidas por mulheres educadoras, na interface com o contexto sócio-histórico".

Em "Corpos e vozes femininas: educação e resistência no cinema argentino", de Natacha Muriel López Gallucci, "apresenta processos de resistência protagonizados por mulheres na cinematografia argentina. [...] analisando oito filmes argentinos trazendo como recorte as representações da voz e do corpo feminino [...] do processo de luta das artistas mulheres para sair do anonimato dos cabarés e entrar no mundo do espetáculo cinematográfico e do trabalho artístico independente".

O Movimento Social das Mães de Plaza de Mayo (Argentina), mundialmente reconhecido, é abordado por Nora Merlin em "Trauma e memória" que recorre aos fundamentos de Freud, afirmando que não há diferenças entre os mecanismos individuais e coletivos para elaboração da memória. No entanto, em se tratando da situação das Mães de Plaza de Mayo, foi o trauma que fez se tornar público o amor na memória coletiva.

A Educação Feminina em instituições escolares é abordada em dois textos, embora a partir de perspectivas diferentes. Samara Mendes Araújo Silva analisa os colégios confessionais católicos no século XX, e Laura Maria Silva Araújo Alves em instituições de assistência na virada do século XIX para XX. Em comum as instituições educacionais analisadas, além de serem exclusivas para mulheres, atuavam sob a égide da formação moral e religiosa, destinando as educandas a se tornar "mães de família". Em "Ritos, Rituais e Rotina: educação feminina nos colégios confessionais católicos no século XX", a cultura escolar inerente a esses colégios é analisada a partir das memórias daqueles que vivenciaram, ou, presenciaram o cotidiano, denotando a rotina que marcou e formou caráter, condutas sacra e intelectual das educandas. E, em "Abrigar, educar e instruir: a política higienista e a educação de meninas desvalidas nas instituições de assistência no Pará (1850-1910)", a autora analisa a educação feminina realizada sob os auspícios da caridade, da assistência e das orientações da política higienista no atendimento à infância desvalida. As meninas eram encaminhadas pelas autoridades que tinham a função de recolher e enviá-las para instituições escolares que as abrigariam e "lhes dariam instrução, educação e formação moral destinadas a serem "mães de família" ou "filhas de criação"."

Esperamos que a leitura dos textos - individual ou coletivamente - que integram este dossiê possibilitem a interlocução interdisciplinar com o conhecimento da Educação e da História, abrangendo as (inter)conexões no plano 
internacional, nacional e local ao desvelar singularidades e diversidades da situação educacional feminina na História da Educação.

Boa Leitura!

\section{REFERÊNCIAS}

ORGANIZAÇÕES DAS NAÇÕES UNIDAS (ONU). A ONU e as mulheres. s.d. Disponível em: <https://nacoesunidas.org/acao/mulheres>. Acesso em: 08 fev. 2018.

BRASIL. Congresso Nacional. Comissão Parlamentar Mista de Inquérito para Examinar a Situação da Mulher em Todos os Setores de Atividade. Brasília: Senado Federal. Centro Gráfico, 1978. Disponível em: <http://www2.senado.leg.br/bdsf/handle/id/84968>. Acesso em: 08 fev. 2018.

CARDOSO, C. F. História e Paradigmas Rivais. In: CARDOSO, C. F.; VAINFAS, R. (Orgs.). Domínios da História: ensaios de teoria e metodologia. 5. ed. Rio de Janeiro: Editora Campus, 1997.

VIOLÊNCIA contra a mulher: no Brasil e no mundo, dados são assustadores. Revista Glamour, 18 nov. 2017. Disponível em: <http://revistaglamour.globo.com/Lifestyle/ Must-Share/noticia/2017/11/violencia-contra-mulher-no-brasil-e-no-mundo-dados-sao-assustadores.html>. Acesso em: 08 fev. 2018.

PEINADO, M. L. A campanha contra a violência machista \#NiUnaMenos. El País, 29 maio 2015. Disponível em: <https://brasil.elpais.com/brasil/2015/05/28/internacional/1432824490_226268.html>. Acesso em: 08 fev. 2018. 